\title{
Hedging in Modern English
}

\author{
Nona Harutyunyan \\ Yerevan State University
}

\section{Hedging: A General Outline}

The main aim of the present paper is to give a general outline of hedging and hedges by putting forward the ideas of the linguists who have brought a great contribution to the development of this linguistic strategy. My research also focuses on the study of the types of hedges and their function in scientific discourse. Besides, an attempt will be made to find out in what fields of academic papers hedges are more pronounced as well as to illustrate whether there are any fields where the use of hedges is excluded.

In her article "I Think that Perhaps You Should: A Study of Hedges in Written Scientific Discourse" F. Salager-Meyer assumes that one of the most important aspects of scientific discourse is to weigh evidence and draw conclusions from data. Fundamental characteristics of science are uncertainty, doubt and skepticism. Scientists inevitably indicate their attitude in their writings. She states that as science is not the coolly objective discipline as asserted in many textbooks and scientific style guides, academic writing cannot be considered as a series of impersonal statements of facts which add up to the truth. Moreover, research from a variety of disciplines has revealed ways in which academic discourse is both socially situated and structured to accomplish rhetorical objectives. Linguistically these objectives are realized as hedges mostly verbal and adverbial expressions such as can, perhaps, may, suggest, which deal with degrees of probability. They are viewed as devices used to reflect not only fundamental characteristics of modern science, but also the true state of the writer's understanding and state of knowledge. According to F. Salager-Meyer, mild speech conveyed by hedges allows researchers to present themselves as cautious, coy, humble and modest servants of their discipline, and to diplomatically negotiate their claims when referring to the work of colleagues and competitors. Its use originates on logic and semantics, but has lately been developed further in pragmatics discourse analysis so far that it now extends to areas like metacommunication and to communication strategies like mitigation and politeness. Through this extension the concept has lost some of its clarity and sometimes seems to have reached a state of definitional chaos, as it overlaps with several other concepts. Hedging is a significant communicative resource for academics since it both confirms the individual's professional persona and represents a critical element in the rhetorical means of gaining acceptance of claims (Salager-Meyer 1995).

In the article "Hedging Research in Pragmatics: A Bibliographical Research Guide to Hedging" H. Schröder and D. Zimmer showed that the designation hedge/hedging was introduced by G. Lakoff in his article "Hedges: A Study in Meaning Criteria and the Logic of Fuzzy Concepts". In his synchronic, non-contrastive study of the oral and written standard English, Lakoff defines hedges as words whose function is to make meanings fuzzier or less fuzzy. Lakoff argues that the logic hedges require serio-semantic analysis for all predicates. He $(1972,195)$ defines hedges as follows: "For me, some of 
the most interesting questions raised by the study of words whose meaning implicitly involves fuzziness - words whose job is to make things fuzzier or less fuzzy. I will refer such words as hedges". In their further investigation H. Schröder and D. Zimmer pointed out that Zadeh (1972) in his article "Fuzzy-Set-Theoretic Interpretation of Linguistic Hedges" followed Lakoff in using the new designation "hedge" and analyzed English hedges from the point of view of semantics and logics. The author assumes that hedges are operators that act on the fuzzy set representing the meaning of their operands. Furthermore, fundamental contributions were made again by G. Lakoff with the focus on lexicography, and by Rosch from the point of view of cognitive psychology (Schröder, Zimmer 1997).

In general terms hedging represents the use of linguistic devices to decrease the writer's responsibility for the extent of and the truth value of propositions/claims, to show hesitation or uncertainty and to display politeness and indirectness in order to reduce the impression on the writer or the reader (E. Hinkel 1997).

As the saying goes, hedges express politeness, vagueness, mitigation, hesitation, tentativeness, etc. They can also be examined as adverbials, epistemic verbs, clausal structures, hypothetical constructions and the anticipatory it-clausal construction. The taxonomy of hedges presented by F. Salager-Meyer represents the most widely used hedging linguists have come across in various types of scientific texts (Salager-Meyer 1995):

Modal Auxiliary Verbs:

Such diseases may be sufficient to explain chronic pain without invoking other factors.

Modal Lexical Verbs:

We believe that syntactic drag-chains are more limited in scope than is sometimes assumed.

Adjectival, Adverbial and Nominal Modal Phrases:

It is possible that they know about interactions between medicine and are best able to prevent them.

Approximators of Degree, Quantity, Frequency and Time:

Approximately 30000 poor residents were displayed from their homes in Atlanta by gentrification.

Introductory Phrases:

It is our view that there are no formal constraints on possible re-analyses beyond the constraints imposed by a theory of grammar.

If Clauses:

If inflected, the living of the vagina becomes inflamed and the vagina area reddens.

Compound Hedges:

It would appear that the analysis does not hold much promise of overcoming the technical problems. 
It appears that a hedge is a "textual phenomenon" and "a virtual quality" of a text. Hedges are of course present at various levels of textualization, but are not inherent characteristics of a text. A text does not contain hedges, but gets them through the authorreader interaction (Markkanen, Schroder 1997).

\section{Hedges in English Scientific Discourse}

That hedges are actually used in scientific discourse, which is supposed to be above all rational and neutral, is connected with the fact that scientific discourse obeys the same mechanisms as ordinary everyday communication does, although it tries to hide this, more or less successfully, by using a code of its own. It is speculated here that science is not only content, that is, scientific texts are not only content-oriented and informative, but also aim at convincing and influencing their audience (Markkanen, Schroder 1997).

To our knowledge the rhetorical style of a scientific text is not merely a decorative addition to an otherwise informative text, rather form and content are inseparable (Stolze 1992:232). Furthermore, it can be assumed that in academic papers the use of hedges varies according to the field the writer represents. Salager-Meyer $(1993,1994)$ showed that medical editorials and review articles are more heavily hedged than research papers and case reports. She argues that the stronger the generation and the claim to universality (review papers and editorials), the more hedged the discourse. Editorials and review articles, which evaluate, persuade or argue and appeal to a broad audience, will have many hedged statements. Research papers will be in the middle, and case reports will be at the end.

Presumably as case reports are clinical observations of a single, generally rare and even unique entities, they are almost purely descriptive and relatively unhedged. Typical of case reports are short-story and anecdote-like sentences. By contrast, review articles collect, select, order and interpret the huge outpouring of scientific reports and present relevant findings and generalizations in a form useful for researchers outside the immediate group working on a given program. This is why in almost every one of the review paper statements, there is as Bazerman and Paradis say (1990:60) "some qualifying adverb or adjective that makes the statements more cautious" (Salager-Meyer 1995):

It has been proposed that this category should be derived much higher in the tree, probably directly dominated by $S$.

The frequency of occurrence and types of hedges are not evenly distributed throughout different sections of academic papers (Bants 1994, Salager-Meyer 1994). The typical Introduction section of academic papers (Swales 1990a) includes a survey of the field. It is a hypothesis-making opening where the unknown or poorly understood is delineated and where scientists mention (mostly with hedge-attributing verbs such as to indicate, to seem, to suggest) previous research which bears in the same issue as the one their article deals with:

Although this year can justifiably be regarded as a successful one for the tries I don't suggest that great value will be needed to maintaining a balance between the three facets. 
In the Introduction sections of academic papers, then, hedges serve the purpose of building arguments to support the researcher's own work. As described in Skelton (1998) the Introduction of a scientific article is almost as tentative as an Arts paper.

Hedges appear least in the almost purely factual Methods section, the least descriptive and commentative section of academic papers where confirmatory statements are the rule:

We brought about to upsurge by $18 \%$ for legal entities and by over 97\% for natural people.

The Results section is also described by a relative absence of hedging devices, but when they do appear they tend to foreshadow the discussion:

One explanation could be that the rules and the conditions underlying such diverse phenomena as article selection, prenominalization are very similar if not identical.

The incidence of hedging seems to be much higher in the Discussion/Conclusion sections of academic papers. It is in these two discursive and speculative sections that authors put forward controversial ideas or interpretations and hence feel the need of protecting themselves from counter argument. In the Discussion section Hyland analyzed instances of hedging rose to one in every 36 words. This reinforces Myer's (1989) contention that most hedging occurs in the Discussion sections of research articles because it is here that an author needs to show commitment while leaving open the possibility of being mistaken. In similar vein Salager-Meyer (1994) summed up the distribution of "vague expressions" and other hedging strategies in medical research papers as being clustered in the Introduction and Discussion, whose language she characterized as being general and vague. A high incidence of hedges in the Discussion section of a research paper is to be expected, because it is in this section that authors seek to demonstrate their relevance to the body of scientific knowledge (Salager-Meyer 1995):

As nice as these benefits are, they are unlikely to provide strategic advantage.

However, the use of hedges is not alien to writers in science and technology either. Duboia (1987:15) discusses the myth of perfect objectivity in science noting that "it has been shown that the scientist can unobtrusively inject his personal view into his communication" by using linguistic items that express uncertainty or impreciseness. Similarly, Butler (1990) shows the importance of modals in English biological and physical texts, in which they "serve the weighing of evidence and the careful drawing of conclusions from data, in the making of claims from evidence, and more particularly in making generalizations about what is possible in the behavior of universe, on the basis of observation of what actually happens" (Butler 1990:139). 
In the book "Hedging and Discourse: Approaches to the Analysis of a Pragmatic Phenomenon in Academic Texts" R. Markkanen and H. Schroder showed that the amount of hedging may depend on individual language user's position vis-a-vis the audience and even on his/her personality. According to them, there is, thus, room for individual style in the use of hedges even in academic writing. A skillful writer may also use them for his/her own scientific purposes. The linguists mentioned above indicated that in his analysis F.R. Leavis' literary-critical text "The Great Tradition", Simpson (1990) showed that Leavis' modalized information that was not "risky" or controversial and left controversial information unmodalized. The effect of this, as Simpson $(1990,91)$ pointed out, that important questions concerning the canon of English literature could be glibly passed over, and, at the same time attention could be deflected toward issues that were, by contrast, less significant and more peripheral". Thus, R. Markkanen and H. Schroder concluded that the pattern of hedging used by an individual writer would become really significant when we thought of the effect that it might have on readers, of how it would direct the readers to evaluate information (Markkanen, Schroder 1997).

Linguists claim that hedging is an important interactional strategy both in spoken and written communication. Thus, to be effective communicators a feel should be acquired for its appropriate use in different communication situations. It is therefore indicated that - in addition to the analysis of hedges and hedging for their own sake-there have been studies of a more applied kind. These studies aim at finding ways of making communication more effective through providing communicators in different areas of life with both knowledge about hedges and the opportunity to develop their skill in using them. This practical aim is evidently shown in studies of hedging at least in the following areas presented by R. Markkanen and H. Schroder:

1. Contrastive/cross language analysis and comparative stylistics

2. Translation studies, e.g., studies concerned with target-language oriented translation, studies on the equivalence of effect between source and target texts, problems connected with text types in different cultures, and 'untranslatable' linguistic and cultural phenomena

3. Studies on teaching writing in the mother tongue and the readability of texts

4. Studies on foreign language teaching, particularly on teaching writing in a foreign language, which also includes contrastive rhetoric, that is, the comparison of culturebound text conventions

5. Intellectual communication studies, that is, studies on the reception of texts written in a foreign language (Raija Markkanen and Hartmut Schroder 1997).

R. Markkanen and H. Schroder illustrate that teaching the appropriate use of hedges, like other pragmatic phenomena, can be very problematic for several reasons. According to them, one reason is apparently that hedges get their meaning through the context in which they occur. Another reason is that their use is often connected with the speakers/writers' values and beliefs, even their personalities, which make teaching them a delicate matter. As using hedging expressions appropriately may cause problems in some communicative situations even in the mother tongue, the linguists mentioned above suggest that it is no wonder that it is problematic in a foreign language. To their 
minds, this is because the rules of appropriateness vary across cultures. And as to become effective communicator in a foreign language, learners have to acquire these rules, particularly since transfer from the mother tongue is possible also in this area. They illustrated Skelton's analysis which suggests that the skillful use of hedges, which requires subtlety and sophistication even in the mother tongue is clearly part of a language user's pragmatic competence, lack of which may lead in foreign language use to mistakes that are more serious that, for example, grammatical errors. This is because pragmatic errors are not so "obviously erroneous" as faulty syntax. They only make the foreign language user sound, in the case of hedging, more impolite or aggressive, more tentative or assertive than he/she intends to be, which they may even lead to a communicative failure. Foreign language learners seem to prefer the more explicit kind of modification to the implicit ones. Hence the authors conclude that in order to sound native-like in a foreign language a speaker or a writer should, then, have a rich repertoire of hedging expressions at his/her disposal and use an appropriate amount of them (Markkanen, Schroder 1997).

An attempt has been made in this paper to show the importance of the phenomenon that appears to be called hedge/hedging for different areas of language use. Linguists apparently admit the difficulty connected with this linguistic strategy. The results show that it expresses politeness, vagueness, mitigation, hesitation, tentativeness, etc. It can as well be examined as adverbials, epistemic verbs, clausal structures, hypothetical constructions and the anticipatory it-clausal construction. The frequency of occurrence of hedges is not distributed throughout different sections of academic papers. The investigations made by linguists prove that the occurrence of hedges is very high in the Discussion/Conclusion sections of academic papers. By contrast, the incidence of hedges is least apparent in the factual Methods section and the Results section which is characterized by a relative absence of hedging devices.

\section{References:}

1. Hinkel, E. (1997) Indirectness in Academic Writing. / Journal of Pragmatics, N27.

2. Lakoff, G. (1972) Hedges: A Study in Meaning Criteria and the Logic of Fuzzy Concepts. / Papers from the $8^{\text {th }}$ regional meeting of the Chicago Linguistic Society. Chicago.

3. Markkanen, R and Schroder, H. (2000) Hedging: A Challenge for Pragmatics and Discourse Analysis. Berlin: Mouton de Gruyter.

4. Markkanen, R and Schroder, H. (1997) Hedging and Discourse: Approaches to the Analysis of a Pragmatic Phenomenon in Academic Texts. Berlin: Mouton de Gruyter.

5. Salager-Meyer, F. (1995) I Think that Perhaps You Should: A Study of Hedges in Written Scientific Discourse. / The Journal of TESOL 2/2. Washington DC.

6. Schröder, H. and Zimmer Z. (1997) Hedging Research in Pragmatics: A Bibliographical Research Guide to Hedging. / Ed. by R. Markkanen \& H. Schröder, 249271. Berlin: Walter de Gruyter. 


\section{Sources of Data:}

1. Boost Your Child's Language Skills. America's 1 family magazine. Woodland Hills, California: Windson Publishers.

2. Mugan, J. Neurolinguistics. Linguistic-Death-in Life. Surrey: University of Surrey Press.

3. Lyman, A. Benefits. Oxford: OUP.

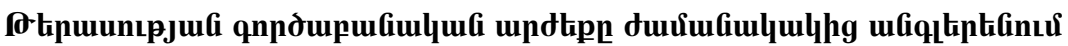

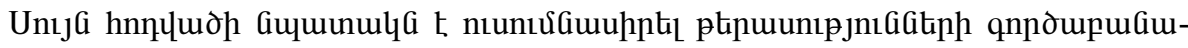

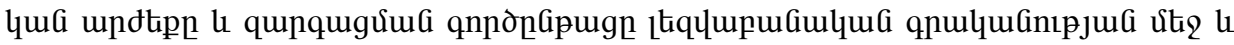

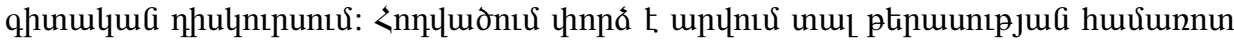

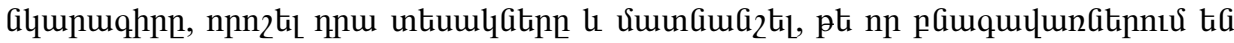

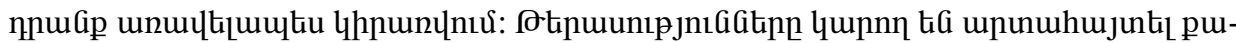

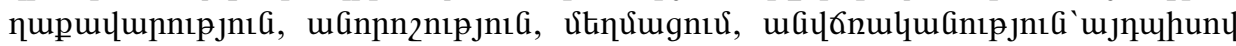

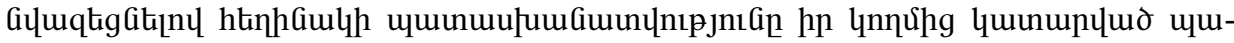

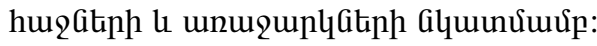

